\title{
MICRORREGIÃO 09 DE PRESIDENTE PRUDENTE/SP - PRAÇAS E PARQUES
}

Leila Barchi Domingues, Jayne Lopes Moura, Yeda Ruiz Maria, Sibila Corral de Arêa Leão Honda.

Universidade do Oeste Paulista - UNOESTE, Faculdade de Engenharias e Arquitetura e Urbanismo, Presidente Prudente, SP. E-mail: yeda rm@hotmail.com

\section{RESUMO}

Além de apresentar uma diversidade morfológica, a praça tem características de espaço coletivo, lugar de manifestação, de culto e de ritos, propício à interação social. Essencial, portanto que o espaço praça seja de qualidade para a população. Em vários países, políticas urbanas destacam a questão da melhoria da qualidade de vida nas grandes cidades por meio do resgate de espaços públicos e coletivos, assim como de estruturas arquitetônicas degradadas. No Brasil o processo de urbanização normalmente acontece de forma não planejada ou inadequada, suas cidades têm dificuldade na implantação de áreas urbanas para formar um sistema de espaços livres públicos coeso e completo, que atenda de maneira ampla e coerente toda a cidade. Portanto buscar-se-á aprofundar os conhecimentos a respeito das áreas verdes urbanas, praças e parques urbanos da microrregião 09 do município de Presidente Prudente-SP. A metodologia será através de levantamento bibliográfico, de pesquisa documental e de levantamentos físico territoriais urbanísticos.

Palavras-chave: Praças e parques; Microrregião 09, Presidente Prudente - SP.

\section{MICROREGION 09 THE PRESIDENTE PRUDENTE / SP - SQUARES AND PARKS}

\begin{abstract}
In addition to presenting a morphological diversity, the square has features of collective space, manifestation of place of worship and rites, conducive to social interaction. Essential, so that the space is square quality for the population. In many countries, urban policies highlight the issue of improving the quality of life in large cities through the rescue of collective and public spaces, as well as degraded architectural structures. In Brazil, the urbanization process usually takes place in an unplanned or inadequate, their cities have difficulty in the implementation of urban areas to form a cohesive and complete public open spaces system that meets a broad and coherent way across town. So will seek to deepen the knowledge about the urban green areas, squares and urban parks microregion 09 in the city of Presidente Prudente-SP. The methodology will be through literature, documentary research and urban territorial physical surveys.

Keywords: Squares and parks; Microregion 09, Presidente Prudente - SP.
\end{abstract}




\section{INTRODUÇÃO}

Os espaços urbanos são importantes elementos na estrutura das cidades, exercem papéis tanto funcionais como para a circulação urbana, sociais e culturais através do convívio público, como ambientais na conservação e requalificação ambiental, não devendo ser negligenciados.

Espaços urbanos são definidos por Magnoli (1986) como sendo os espaços livres de edificação, como as matas, jardins públicos ou privados, ruas e avenidas, vazios urbanos, praças e parques. Formam um sistema complexo, que relaciona, conecta e complementa o todo.

As praças, exercendo seu papel no sistema complexo urbano, constam nas cidades brasileiras desde os primeiros séculos da colonização, e, juntamente com os largos, eram fundamentais na estruturação urbana e pontos de concentração da população (MAGNOLI, 1986).

Além de apresentar uma diversidade morfológica, a praça tem características de espaço coletivo, lugar de manifestação, de culto e de ritos, propício à interação social (CALDEIRA, 2007). Essencial portanto que o espaço praça seja de qualidade para a população.

Neste sentido Caldeira (2007) observa que atualmente o espaço da praça perde prestígio como espaço de sociabilidade, local de encontro e de lazer, mas destaca-se como espaço livre, espaço de circulação e área verde. Em vários países, políticas urbanas destacam a questão da melhoria da qualidade de vida nas grandes cidades por meio do resgate de espaços públicos e coletivos, assim como de estruturas arquitetônicas degradadas (CALDEIRA, 2007).

Entretanto a questão do uso do solo costuma negligenciar a reserva de áreas para essa finalidade, com leis de zoneamento e uso do solo que pouco efetivamente estabelece proteção e/ou ampliação das áreas verdes públicas (CUNHA, 2003).

Como no Brasil o processo de urbanização normalmente acontece de forma não planejada ou inadequada, suas cidades têm dificuldade na implantação de áreas urbanas para formar um sistema de espaços livres públicos coeso e completo, que atenda de maneira ampla e coerente toda a cidade (MENNHE e COELHO, 1999).

Neste contexto se entende que as praças e parques são por excelência espaços públicos e áreas verdes de direito para a recreação e lazer da população urbana. Assim sendo, com base nestes conceitos apresentados, busca-se, por meio desta pesquisa aprofundar os conhecimentos a respeito das áreas verdes urbanas - praças e parques urbanos, na cidade de Presidente Prudente $\mathrm{SP}$, verificando-se, quais que sofreram alteração de uso, mapeando-as e identificando seus atuais usos e ocupação, mais especificamente na microrregião 09.

A metodologia a ser seguida será baseada na investigação qualiquantitativa, utilizando-se de levantamento bibliográfico, de pesquisa documental, de levantamentos físico territoriais urbanísticos das áreas verdes urbanas.

\section{PRESIDENTE PRUDENTE - SP E A MICRORREGIÃO 09}

A cidade de Presidente Prudente, localizada no extremo oeste paulista - região denominada Alta Sorocabana - foi fundada no dia 14 de setembro de 1917 e, segundo o senso do IBGE (2015), abriga atualmente uma população de 222.000 habitantes.

A expansão da cidade é apontada por Honda et al (2015) como uma cidade que teve sua dinâmica direcionada para sudoeste, deixando grandes vazios urbanos, tendo provocado regularização de loteamentos, lotes e, inclusive, de áreas devolutas.

O artigo 12 do Plano Diretor (2008) da cidade estabelece que os loteamentos "deverão" atender certas relações de proporcionalidade e características do município, bem como a constituição das áreas públicas por: áreas institucionais, sistema viário, áreas de preservação ambiental e/ou non edificandi, quando for o caso.

Assim sendo, busca-se, por meio desta pesquisa, realizar um levantamento de usos das praças e parques de Presidente Prudente - SP, locadas em 4 (quatro) bairros que compõem a 
microrregião 09: Cidade Universitária, Jardim Bongiovani, Jardim dos Pioneiros e Vila Liberdade (figura 01).

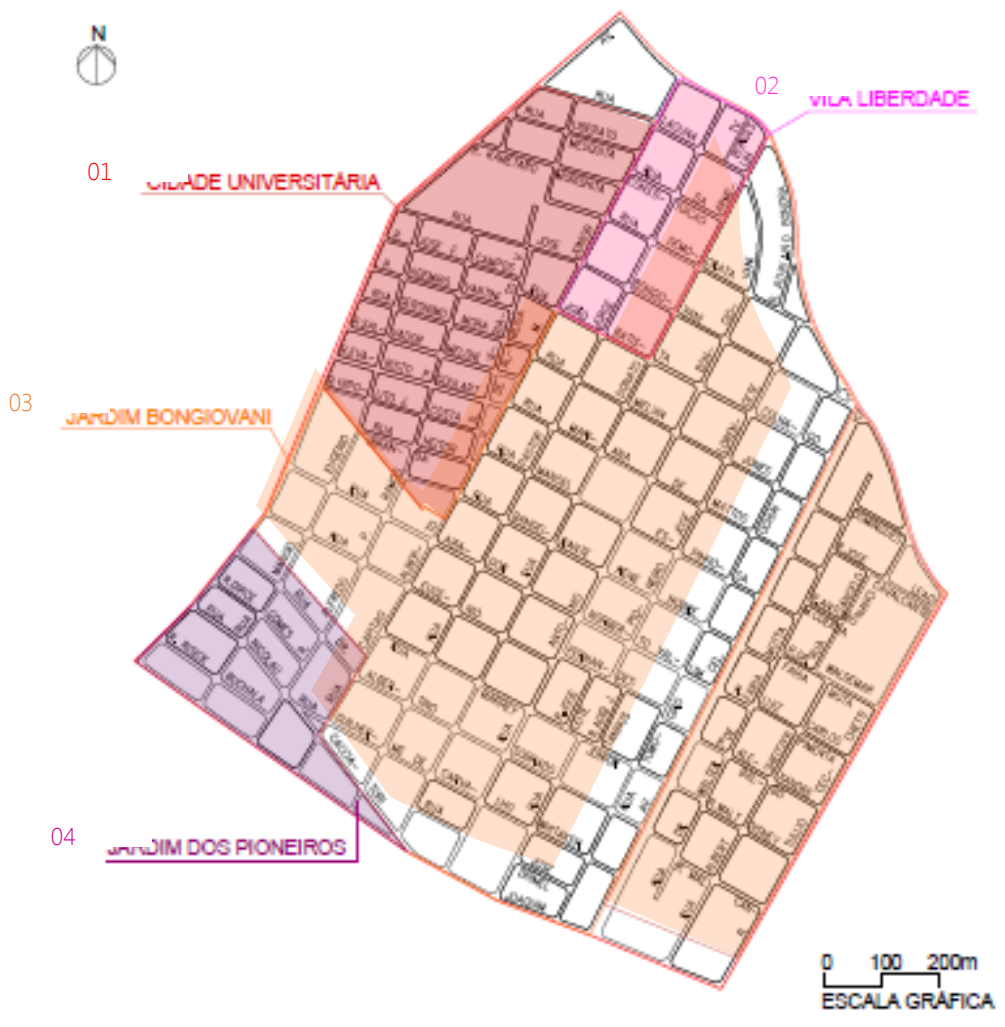

Figura 01.Bairros da microrregião 09 - Presidente Prudente/SP.

Fonte: Prefeitura Municipal de Presidente Prudente, 2015. Editado pelas autoras, 2016.

\section{Bairro Cidade Universitária}

No bairro Cidade Universitária há uma área de recreação e lazer que ocupa três quadras (figura 02).

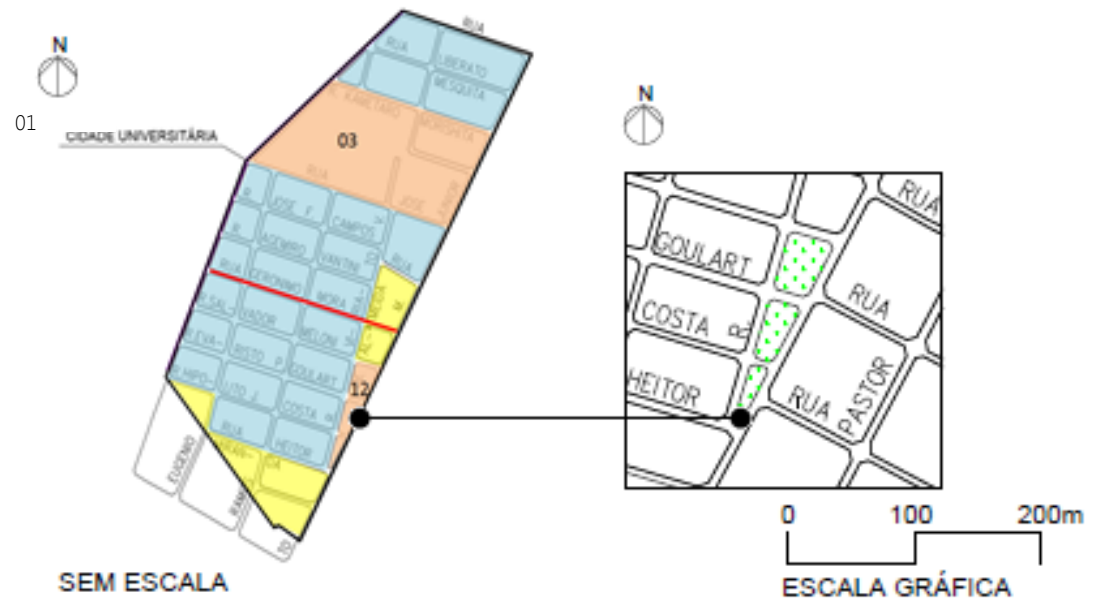

Figura 02. Bairro Cidade Universitária e sua área de lazer e recreação.

Fonte: Prefeitura Municipal de Presidente Prudente, 2015. Editado pelas autoras, 2016.

O local apresenta uma quantia razoável de assentos, mesas cobertas e descobertas, brinquedos infantis, lixeiras, postes de iluminação e árvores (figura 03). No fim da tarde é o período que há mais movimento na praça, tanto dos moradores de residência familiar quanto dos estudantes universitários que moram pela vizinhança. São essas pessoas que acabam cuidando das 
árvores da praça. Todos estes mobiliários estão espalhados pelos passeios públicos e caminhos, entretanto estão em más condições para o seu devido uso.

\section{Bairro Jardim Bongiovani}

No Bairro Jardim Bongiovani foram encontradas duas praças, as quais estão alocadas e enumeradas no mapa a seguir.

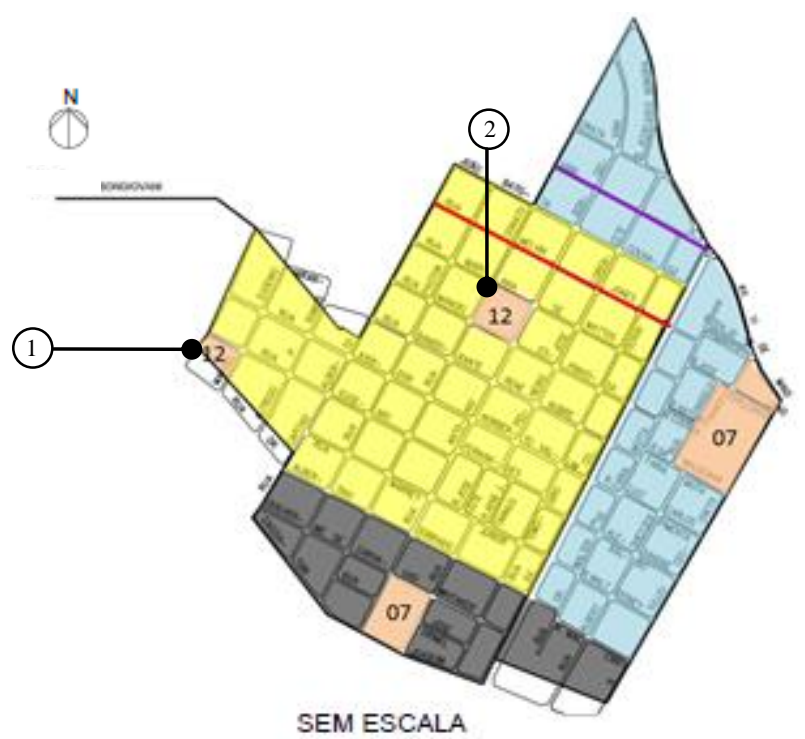

Figura 03. Mapa do Bairro Jardim Bongiovani e suas áreas de recreação. Fonte: Prefeitura Municipal de Presidente Prudente, 2015. Editado pelas autoras, 2016.

A praça de número 01 do Bairro Jardim Bongiovani, localizada na extremidade do bairro, pertencendo também ao Bairro Jardim Pioneiros, possui apenas assentos e árvores como mobiliários urbanos que não suprem a necessidade de sombreamento do local. Por isso, a praça é utilizada apenas como ponto de encontro noturno do público das boates próximas.

Em contrapartida a praça, enumerada como 02, se localiza próxima ao centro do bairro, esta bem cuidada, é acessível e limpa, possui parquinho infantil, academia ao ar livre, espaços amplos para o lazer e duas lanchonetes em suas extremidades, resultando em considerável fluxo de pessoas em horários variados.

\section{Vila Liberdade}

No bairro Vila Liberdade não foi encontrada espaços públicos de lazer que se configurem como praças e/ou parques. Nas visitas in loco foi perceptível que seus moradores fazem uso dos espaços de lazer dos bairros vizinhos.

\section{CONSIDERAÇÕES FINAIS}

Os levantamentos e análises realizadas evidenciaram ainda mais o fato de que os mobiliários são elementos estruturadores das áreas de lazer. Esses espaços coletivos devem ser adequados aos lazer que seu entorno necessita.

A microrregião 09 se encontra carente de espaços desta natureza que soem positivamente aos nossos olhos. Cabe ao pode público local realizar planos e projetos que atendam a essa demanda, não excluindo o fato de que a população deve estar participativa destas ações.

\section{REFERENCIAS}


CALDEIRA, J.M. A praça brasileira, trajetória de um espaço urbano: origem e modernidade. Doutorado em História, IFCH/UNICAMP, 2007.

CUNHA, R.D.A. Os espaços públicos abertos e as leis de uso e ocupação do solo: uma questão de qualidade para ambientes sustentáveis. III Enecs - Encontro Nacional sobre Edificações e Comunidades Sustentáveis. 2003.

HONDA, Sibila Corral de Arêa Leão; VIEIRA, Marcela do Carmo; ALBANO, Mayara Pissutti e MARIA, Yeda Ruiz. Planejamento ambiental e ocupação do solo urbano em Presidente Prudente (SP). Urbe, Rev. Bras. Gest. Urbana [online]. 2015, vol.7, n.1, pp. 62-73. Epub Abr-2015. ISSN 2175-3369.

IBGE - Instituto Brasileiro de Geografia e Estatísticas. Dados gerais do município de Presidente Prudente - SP. 2015 Disponível em: http://cidades.ibge.gov.br/xtras/perfil.php?codmun=354140.

MAGNOLI, M.M O parque no desenho urbano. In:TURKIENICZ, B. \& MALTA, M. Desenho urbano, Anais do II SEDUR, São Paulo, PINI/ FINEP, CNPq, 1986. p. 111- 120.

MENNHE, M.H.; COELHO, A.M. Características do sistema de parques públicos urbanos da cidade de São Paulo. In: ENTAC, 8, 2000, Salvador. ANAIS, Salvador: ANTAC., 2000. 8 p. CD-ROM. Seção artigos.

PRESIDENTE PRUDENTE (2008). Plano Diretor. Presidente Prudente: Prefeitura Municipal, 2008. 